\title{
The Firehawk stent: a review of a novel abluminal groove- filled biodegradable polymer sirolimus-eluting stent
}

\author{
El stent Firehawk: revisión de un nuevo stent de polímero biodegradable \\ liberador de sirolimus desde ranuras abluminales
}

Daniel Grubman ${ }^{1}$, Yuichi Saito ${ }^{1}$, Alexandra Lansky',

\begin{abstract}
Despite recent advances in drug-eluting stent (DES) technology, late adverse events remain concerns after percutaneous coronary intervention. The persistence of polymer material on DES has been suggested as a trigger for chronic inflammation. The Firehawk, a novel DES, has a unique design with recessed abluminal grooves, to which sirolimus and biodegradable polymer are applied. The Firehawk stent is designed to minimize polymer volume and antiproliferative drug concentration to reduce inflammation and hypersensitivity reactions. Several recent trials have reported the clinical outcomes of this device. This article provides a review of the current clinical evidence concerning the Firehawk stent.
\end{abstract}

Keywords: coronary disease, drug eluting stent, biodegradable polymer.

\begin{abstract}
RESUMEN
A pesar de los recientes avances en la tecnología con los stents liberadores de farmacos (DES), los eventos cardíacos adversos tardíos permanecen siendo una preocupación. La presencia de polímeros no absorbibles se ha sugerido como causa de inflamación crónica. El stent Firehawk presenta un diseño muy especial que combina un polímero absorbible con localización abluminal de reservorio de la droga, lo que potencialmente podría reducir la inflamación y las reacciones de hipersensibilidad.

Se han realizado varios estudios aleatorizados y observacionales con este diseño de stent y en este artículo se hace una revisión de los datos clínicos más relevantes con este diseño de DES
\end{abstract}

Palabras clave: enfermedad coronaria, stent farmacológico, polímeros biodegradables.

Revista Argentina de Cardioangiología Intervencionista 2019;10(2):73-77. https://doi.org/10.30567/RACI/201902/0073-0077

\section{INTRODUCTION}

Percutaneous coronary intervention (PCI) has revolutionized the treatment of patients with coronary artery disease, which is one of the leading cause of death worldwide ${ }^{1}$. While the introduction of bare metal stents improved procedural success and acute outcomes when compared to balloon angioplasty ${ }^{2}$, the rate of in-stent restenosis remained high. Drug-eluting stents (DES) were developed to deliver antiproliferative drugs to the vessel wall, resulting in significantly reduced angiographic and clinical measures of restenosis ${ }^{3}$. To date, DES have been shown to have superior safety and efficacy compared to bare metal stents ${ }^{4}$, and new-generation DES, which have incorporated thinner struts, new antiproliferative drugs with better elution profiles, and biocompatible polymers, are currently recommended for all patient and lesion subtypes in $\mathrm{PCI}^{5}$. Although new-generation DES include both durable and biodegradable polymer-coated stents, antiproliferative drugs and the lifelong presence of durable polymer are associated with chronic local inflammation, hypersensitivity reactions, delayed reendothelialization, impaired endothelial function, and neoatherosclerosis, leading to late adverse clinical events ${ }^{6-9}$.

1. Yale University School of Medicine, New Haven, CT, USA;

2. Barts Heart Centre, London and Queen Mary University of London, London, UK.

$\triangle$ Correspondencia: Alexandra Lansky, MD. Division of Cardiovascular Medicine, Yale School of Medicine, 135 College Street, Suite 101, New Haven, Connecticut 06510, Phone: 1-203-737-2142, Fax:+1-203-737-7457. alexandra.lansky@yale.edu

Conflictos de intereses: Alexandra Lansky has received a research grant and speaker fee from Microport. The other authors have reported no conflict of interests.

Recibido: 31/05/2019| Aceptado: 07/06/2019
The Firehawk stent (Shanghai MicroPort Medical Group, Shanghai, China) is a novel thin strut cobalt-chromium coronary stent with sirolimus and biodegradable polymer that are localized to a series of abluminal grooves. The design of the stent minimizes polymer burden and reduces drug concentrations, making it more biocompatible than a conventional DES. Recently, several clinical studies have reported the safety and efficacy of the Firehawk. This review summarizes the unique design and concept of this device and the clinical evidence of the Firehawk stent.

\section{STENT DESIGN AND CONCEPT OF THE FIREHAWK}

The Firehawk is a balloon-expandable L605 cobalt-chromium stent with a strut thickness of $86 \mu \mathrm{m}$ pre-mounted on a rapid exchange delivery system. A novel feature of this device is the unique set of recessed abluminal grooves along its outer surface containing a D,L-polylactic acid polymer of $10 \mu \mathrm{m}$ thickness, which provides for the controlled and targeted release of the antiproliferative drug sirolimus into the vessel wall (Figure 1). Polylactic acid polymer is biodegradable and is readily metabolized to carbon dioxide and water. Inflammation associated with the polymer subsides as it degrades and the drug is delivered. The remainder of the stent's surface $(>80 \%)$ is metallic. The drug density of sirolimus is $0.3 \mu \mathrm{g} / \mathrm{mm}^{2}$, with $90 \%$ of the dose released in the first 90 days. The polymer degrades from the stent over the course of 6 to 9 months, leaving only the metallic stent behind. The characteristics of the Firehawk stent is summarized in Table $\mathbf{1 .}$

The Firehawk stent is designed to minimize polymer burden and reduce drug concentrations in the vessel wall. In fact, it represents the lowest polymer volume and drug concentration among currently available biodegradable polymer $\mathrm{DES}^{10}$. In a 


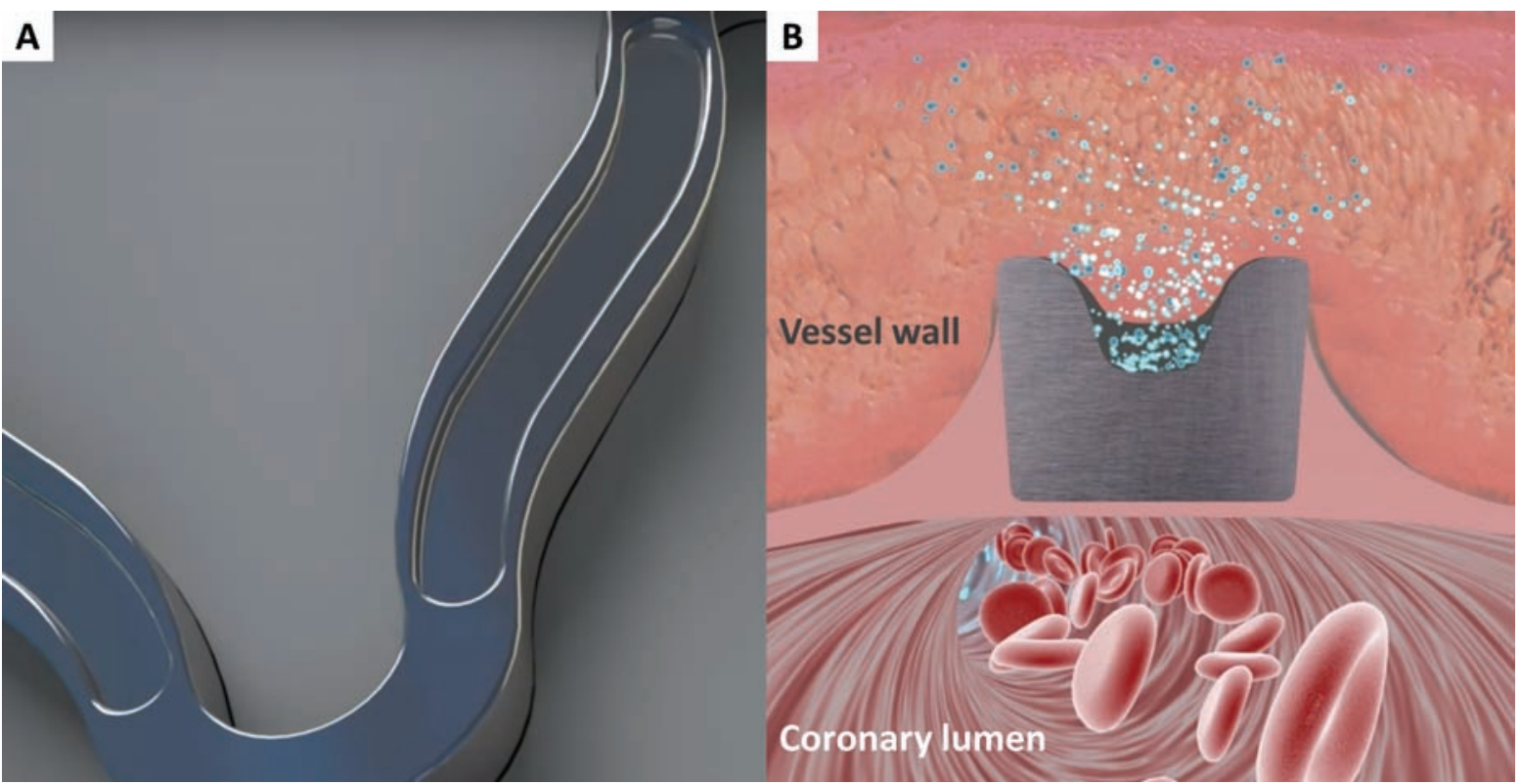

Figure 1 Stent appearance and conceptual drug releasing in the vessel wall. (A) Recessed abluminal grooves at the outer surface. (B) Abluminal grooves contain sirolimus and biodegradable polymer to provide controlled and targeted antiproliferative effect.

TABLE 1. The characteristics of the Firehawk stent.

\begin{tabular}{|l|l|}
\hline Platform & \\
\hline Stent material & L605 cobalt-chromium with abluminal grooves \\
Strut thickness & $86 \mu \mathrm{m}$ \\
Number of links & 2 or 3 \\
Stent diameter & $2.25,2.50,2.75,3.00,3.50,4.00 \mathrm{~mm}$ \\
Stent length & $13,16,18,21,23,26,29,31,33,35,38 \mathrm{~mm}$ \\
\hline Carrier & \\
\hline Polymer & D,L-polylactic acid biodegradable polymer \\
Coating & Abluminal \\
\hline Drug & \\
\hline Sirolimus & $0.30 \mu \mathrm{g} / \mathrm{mm}^{2}$ \\
Release profile & $90 \%$ release by 90 days \\
\hline
\end{tabular}

$2.25 \times 31 \mathrm{~mm}, 2.25 \times 33 \mathrm{~mm}, 2.25 \times 35 \mathrm{~mm}, 2.25 \times 38 \mathrm{~mm}, 2.5 \times 35 \mathrm{~mm}$ and $2.5 \times 38 \mathrm{~mm}$ are not available.

porcine model, the use of abluminal grooves allowed an equivalent concentration of sirolimus to be delivered to the endothelial tissue while decreasing the amount of circulating drug by nearly 7-fold when compared to the conventional Cypher sirolimus-eluting stent (Johnson \& Johnson, New Brunswick, USA) $(113 \mathrm{pg} / \mathrm{ml} \text { vs. } 733 \mathrm{pg} / \mathrm{ml})^{11}$. The Firehawk stent demonstrated lower inflammation scores, and despite its abluminal groove design, was shown to have similar mechanical performance under expansion and contraction when compared to traditional $\mathrm{DES}^{11}$. In the context of these conceptual advantages, the Firehawk stent has been evaluated in clinical trials.

\section{CLINICAL EVIDENCE}

The first-in-man study of the Firehawk was published in 2012. There have been two subsequent randomized control trials (RCT) and one single-arm prospective registry further evaluating the device's performance (Table 2). The first study included only 21 patients with single de novo native coronary lesions at a single Chinese site ${ }^{12}$. Device success was achieved in all but one patient, where the stent deployed with $>30 \%$ residual stenosis that was resolved after post-dilation. Target lesion failure (TLF) - a composite cardiac death, myocardial infarction (MI), and ische- mia-driven target lesion revascularization-was $0 \%$ at 30 days. Follow-up angiography revealed late lumen loss (LLL) of $0.13 \pm 0.18 \mathrm{~mm}$ and $0.16 \pm 0.07 \mathrm{~mm}$ at 4 and 13 months. An optical coherence tomography (OCT) follow-up was performed in 14 patients, suggesting good vessel healing after Firehawk implantation with $96.2 \%$ of struts covered and a low rate of strut malapposition $(0.1 \%)$ (Table 3) $)^{12}$. Although the number of enrolled patients was very limited, this first-in man study provided promising results.

The TARGET I trial was a RCT comparing the performance of the Firehawk stent to the XIENCE durable-polymer everolimus-eluting stent (Abbott Vascular, Santa Clara, USA) in non-complex patients and lesions (Table 2) ${ }^{13}$. The study enrolled 458 patients from 16 Chinese sites, with 227 randomized to the experimental group. The Firehawk had similar LLL to the XIENCE stent at 9 months $(0.13 \pm 0.24 \mathrm{~mm}$ vs. $0.13 \pm 0.18 \mathrm{~mm}, \mathrm{p}$ for non-inferiority $<0.0001)$. Although TLF was a secondary endpoint of this study, its incidence was also equivalent between Firehawk and XIENCE stent at 12 -month follow-up (2.2\% vs. 2.2\%, $\mathrm{p}=1.00)^{13}$. This result reinforced the clinical safety and efficacy of the Firehawk stent compared to the best-in-class XIENCE DES. However, the sample size of the TARGET I trial was calibrated to assess a difference in LLL, and the event rate was low because of strict angiographic and clinical eligibility criteria, limiting the statistical power of this comparison.

TARGET II was a prospective, multicenter, single-arm registry assessing the performance of the Firehawk stent in patients with higher lesion complexity than in the first-inman study and TARGET I trial (Table 2$)^{14}$. A total of 730 patients were enrolled and treated with Firehawk stents in China. In this study, multiple stent implantations into lesions up to $60 \mathrm{~mm}$ in length were allowed. The primary endpoint of the study was TLF at 12 months, which was low (4.4\%) with only one definite or probable stent thrombosis reported. When the participants were divided into three groups according to coronary lesion complexity, patients 
TABLE 2. Clinical trials to evaluate safety and/or efficacy of the Firehawk stent.

\begin{tabular}{|c|c|c|c|c|}
\hline & FIM FIREHAWK $^{12}$ & TARGET I ${ }^{13}$ & TARGET $\|^{14}$ & TARGET All Comers ${ }^{10}$ \\
\hline First published year & 2012 & 2013 & 2014 & 2018 \\
\hline Design & Single-arm registry & $\mathrm{RCT}$ & Single-arm registry & $\mathrm{RCT}$ \\
\hline Comparator & $\mathrm{N} / \mathrm{A}$ & XIENCE & N/A & XIENCE \\
\hline Sample size (n) & 21 & 458 (227 vs. 231) & 730 & 1653 (823 vs. 830) \\
\hline Region & China & China & China & Europe \\
\hline Major inclusion criteria & Single denovo lesion $\leq 30 \mathrm{~mm}$ & Single denovo lesion $\leq 24 \mathrm{~mm}$ & Denovo lesion $\leq 60 \mathrm{~mm}$ & All-comers study \\
\hline Major exclusion criteria & Acute MI & $\begin{array}{l}\text { Age }>75 \text {, acute MI, CTO, } \\
\text { LMT, bifurcation lesion }\end{array}$ & $\begin{array}{l}\text { Age }>75 \text {, acute MI, LMT, } 3 \\
\text { vessel disease, severe Ca }\end{array}$ & None \\
\hline \multicolumn{5}{|l|}{ Patient characteristics } \\
\hline Age (years) & $56.2 \pm 8.9$ & $58.7 \pm 9.4$ & $58.7 \pm 8.9$ & $64.9 \pm 9.8$ \\
\hline Male & $67 \%$ & $69 \%$ & $71 \%$ & $78 \%$ \\
\hline Hypertension & $43 \%$ & $58 \%$ & $60 \%$ & $60 \%$ \\
\hline Diabetes & $14 \%$ & $14 \%$ & $26 \%$ & $24 \%$ \\
\hline Hyperlipidemia & $57 \%$ & $27 \%$ & $34 \%$ & $53 \%$ \\
\hline Prior Ml & $10 \%$ & $20 \%$ & $30 \%$ & $22 \%$ \\
\hline Acute MI & $0 \%$ & $0 \%$ & $0 \%$ & $31 \%$ \\
\hline \multicolumn{5}{|l|}{ Lesion characteristics } \\
\hline $\mathrm{RVD}(\mathrm{mm})$ & $2.88 \pm 0.51$ & $2.87 \pm 0.47$ & $2.79 \pm 0.49$ & $2.77 \pm 0.49$ \\
\hline Lesion length (mm) & $17.7 \pm 6.1$ & $15.7 \pm 7.1$ & $23.9 \pm 13.1$ & $19.0 \pm 11.8$ \\
\hline Diameter stenosis & $68.4 \pm 12.6 \%$ & $66.4 \pm 13.2 \%$ & $71.2 \pm 15.5 \%$ & $71.7 \pm 15.9 \%$ \\
\hline Primary endpoint & TLF at 30 days & LLL at 9 months & TLF at 12 months & TLF at 12 months \\
\hline Results & $0 \%$ & $0.13 \pm 0.24 \mathrm{~mm}$ vs. $0.13 \pm 0.18 \mathrm{~mm}$ & $4.4 \%$ & $6.1 \%$ vs. $5.9 \%$ \\
\hline
\end{tabular}

Only patient and lesion characteristics in the Firehawk group are listed in TARGET I trial and TARGET All Comers study. TLF was defined as a composite of cardiac death, MI, and ischemia driven target lesion revascularization. Sample size and results are shown as the Firehawk vs. XIENCE in TARGET I trial and TARGET All Comers study.

Ca, calcification; CTO, chronic total occlusion; FIM, first in man; LLL, late lumen loss; LMT, left main trunk; MI, myocardial infarction; RCT, randomized control trial; RVD, reference vessel diameter; TLF, target lesion failure.

TABLE 3. Optical coherence tomography substudies.

\begin{tabular}{|c|c|c|c|c|c|c|c|}
\hline & \multirow{2}{*}{$\begin{array}{c}\text { FIM FIREHAWK }^{12} \\
(n=14)\end{array}$} & \multicolumn{3}{|c|}{ TARGET I17 } & \multicolumn{3}{|c|}{ TARGET All Comers 16} \\
\hline & & $\begin{array}{c}\text { Firehawk } \\
(n=20)\end{array}$ & $\begin{array}{l}\text { XIENCE } \\
(n=23)\end{array}$ & $p$-value & $\begin{array}{c}\text { Firehawk } \\
(n=24)\end{array}$ & $\begin{array}{l}\text { XIENCE } \\
(n=28)\end{array}$ & $\mathrm{p}$-value \\
\hline Time (months) & 13 & & 36 & & & 3 & \\
\hline Uncovered struts & $3.8 \%$ & $0.8 \%$ & $0.7 \%$ & 0.53 & $0.1 \pm 0.3 \%$ & $0.0 \pm 0.1 \%$ & 0.26 \\
\hline Malapposition & $0.1 \%$ & $0.08 \%$ & $0.06 \%$ & 0.15 & $1.0 \pm 1.6 \%$ & $1.2 \pm 2.0 \%$ & 0.77 \\
\hline Neointimal thickness $(\mu \mathrm{m})$ & $64 \pm 55$ & $130 \pm 20$ & $130 \pm 20$ & 0.80 & $75.5 \pm 25.8$ & $82.3 \pm 31.1$ & 0.40 \\
\hline
\end{tabular}

FIM, first in man.

in the top SYNTAX score tertile $(>12)$ had a significantly higher rate of TLF compared to those in the intermediate and low tertiles $(7.5 \%$ vs. $3.1 \%$ vs. $2.5 \%, p=0.02) .{ }^{14}$ Thereafter, a patient-level pooled analysis of the TARGET trials was published including 2 -year results. The follow-up data from 1007 patients yielded a TLF incidence of $4.6 \%$ at 24 months with only one case of stent thrombosis $(0.1 \%){ }^{15}$ These findings suggest that the safety of the Firehawk stent is in line with conventional DES. Based on the clinical evaluations in China, the Firehawk stent received a ConformitéEuropéenne mark in 2015. However, neither TARGET I nor II included patients with high-risk clinical (e.g. elderly and acute MI) and lesion (e.g. severe calcification, left main disease, and bypass lesion) profiles. Thus, an all-comers RCT which is adequately powered to assess clinical events was warranted.

The TARGET All-Comers study was a prospective, multicenter, open-label randomized non-inferiority trial again comparing the Firehawk and XIENCE stent (Table 2) ${ }^{10}$. From December 2015 to October 2016, 1653 patients from 21 medical centers in 10 European countries were enrolled and 823 were randomized to treatment with the Firehawk stent. There were no restrictions on the lesion characteristics, PCI procedures, or patient's clinical presentation. The included participants were older than previous studies and acute MI accounted for approximately $30 \%$. The incidence of TLF was $6.1 \%$ in the Firehawk group and $5.9 \%$ in the XIENCE group ( $\mathrm{p}$ for non-inferiority=0.004), which was numerically higher than that in the TARGET I and II (Figure 2). A small but significant difference in the technical success rate favored the XIENCE stent (95.6\% vs. 94.2\%, p=0.01), which may represent a limitation of an open-label device study, in which behavioral differences based on investigator experience cannot be excluded. The angiographic substudy of 176 patients showed that LLL was $0.17 \pm 0.48 \mathrm{~mm}$ and $0.11 \pm 0.52 \mathrm{~mm}$ for patients in the Firehawk and XIENCE groups ( $p$ for non-inferiority $=0.02$ ). In a subgroup analysis, there were no significant between-group differences with respect to prespecified clinical and lesion characteristics. ${ }^{10}$ The TARGET All-Comers study clearly demonstrated that the Firehawk stent is non-inferior to the benchmark XIENCE stent as assessed with the primary endpoint of TLF at 12 months in an all-comers population. Furthermore, the results confirmed the clinical evaluations performed in China, and represent a successful global approval pathway for a Chinese DES in Europe. An OCT substudy of TARGET All-Comers assessed neointimal coverage at 3 months in 36 patients with 52 lesions $^{16}$. The Firehawk and XIENCE groups both displayed near-complete strut coverage, low rate of malappo sed struts, and neointimal thicknesses of $75.5 \pm 25.8 \mu \mathrm{m}$ and $82.3 \pm 31.1 \mu \mathrm{m}$ ( $\mathrm{p}$ for non-inferiority $<0.001$ ). The results of the OCT substudies performed in the first-in-man study, TARGET I trial, and TAR- 


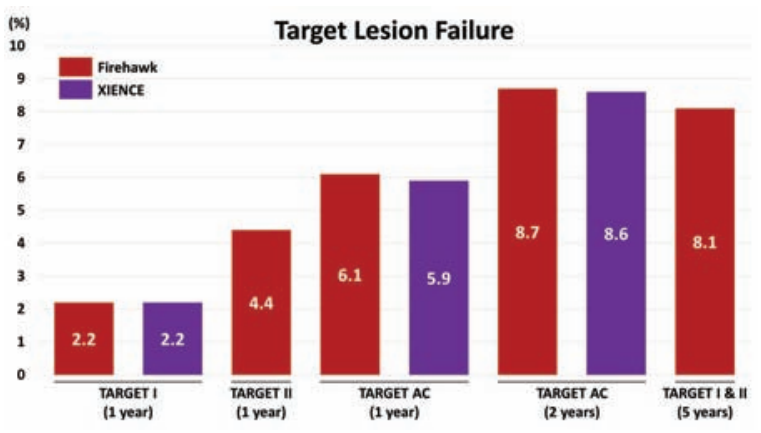

Figure 2 The incidence of target lesion failure in clinical trials. Target lesion failure is defined as a composite of cardiac death, myocardial infarction, and ischemia-driven target lesion revascularization.

GET All-Comers study are summarized in Table 3, indicating consistent vessel healing demonstrated with the Firehawk up to 3 years ${ }^{12,16,17}$. Compared to previous results with other biodegradable polymer DES, OCT findings with the Firehawk stent appears to be favorable ${ }^{16}$. Most recently, the 2-year clinical outcomes of TARGET All-Comers study was published, showing similar safety and efficacy profiles of the Firehawk and XIENCE stents ${ }^{18}$. It is conceivable that the Firehawk is a safe and effective alternative stent to treat patients with coronary artery disease in daily clinical practice.

The Firehawk stent has been tested in patients highly selected by angiographic and clinical characteristics in TARGET I trial, followed by TARGET II which included long lesions and TARGET All Comers study. Accordingly, event rates have been substantially increased in these studies (Figure 2), but the Firehawk stent has shown consistent safety and efficacy. However, whether biodegradable polymer DESs have a clinical advantage is still under deba-

\section{REFERENCES}

1. Naghavi M, Abajobir AA, Abbafati C, et al. Global, regional, and national age-sex specific mortality for 264 causes of death, 1980-2016: a systematic analysis for the Global Burden of Disease Study 2016. Lancet. 2017;390(10100):1151-1210.

2. Serruys $P W$, de Jaegere P, Kiemeneij F, et al. A comparison of balloon-expandable-stent implantation with balloon angioplasty in patients with coronary artery disease. Benestent Study Group. N Engl J Med. 1994;331(8):489-495.

3. Moses JW, Leon MB, Popma JJ, et al. Sirolimus-eluting stents versus standard stents in patients with stenosis in a native coronary artery. N Engl J Med. 2003;349(14):1315-1323.

4. Piccolo R, Bonaa KH, Efthimiou O, et al. Drug-eluting or bare-metal stents for percutaneous coronary intervention: a systematic review and individual patient data meta-analysis of randomised clinical trials. Lancet. 2019. doi: 10.1016/50140-6736(19)30474-X.

5. Neumann FJ, Sousa-UvaM, Ahlsson A, etal.2018ESC/EACTS Guidelineson myocardial revascularization. Eur Heart J. 2019;40(2):87-165.

6. Finn AV, Nakazawa $G$, Joner M, et al. Vascular responses to drug eluting stents: importance of delayed healing. Arterioscler Thromb Vasc Biol. 2007;27(7):1500-1510.

7. Otsuka F, Vorpahl M, Nakano M, et al. Pathology of second-generation everolimus-eluting stents versus first-generation sirolimus- and paclitaxel-eluting stents in humans. Circulation. 2014;129(2):211-223.

8. Joner M, Finn AV, Farb A, et al. Pathology of drug-eluting stents in humans: delayed healing and late thrombotic risk. J Am Coll Cardiol. 2006;48(1):193-202. te. A pooled analysis of 3 DES RCTs reported lower rates of definite stent thrombosis and clinically indicated target lesion revascularization at 4 years with biodegradable polymer DES implantation compared to durable polymer DES, but the tested durable polymer devices were first-generation DES in this investigation ${ }^{19}$. On the other hand, a recent meta-analysis which included 16 randomized DES trials demonstrated similar safety and efficacy of biodegradable polymer DES in terms of TLF and stent thrombosis during a mean follow-up period of 26 months compared to new-generation durable polymer DES, failing to show a clinical benefit ${ }^{20}$. It is difficult to demonstrate the potential superiority of biodegradable polymer DES at mid-term follow-up (e.g. 2 years). The patient-level pooled analysis form TARGET I and II trials showed long-term results of the Firehawk stent. ${ }^{21}$ However, the rate of TLF $(8.1 \%$ at 5 years) was relatively low (Figure 2), and the result was only for the Firehawk stent without any comparator. The longterm follow-up data from the all-comers RCT is warranted to differentiate the clinical usefulness of the Firehawk stent with conceptual advantages (i.e. minimum volume of biodegradable polymer and antiproliferative drug), and the TARGET All-Comers study will continue to evaluate clinical outcomes up to 5 years.

\section{CONCLUSION}

The Firehawk stent has a unique design with recessed abluminal grooves facing the vessel wall, to which sirolimus and biodegradable polymer are applied. This novel DES is designed to minimize polymer volume and antiproliferative drug concentration to reduce inflammation and hypersensitivity reactions in the coronary vessel wall. Recent clinical evidence has supported the safety and efficacy of the Firehawk stent with non-inferiority to the XIENCE stent in the RCTs. Future investigation will elucidate whether the Firehawk has the potential to further improve clinical outcomes.
9. InoueT, CroceK, Morooka T,SakumaM, NodeK, Simon DI. Vascularinflammation andrepair:implicationsforre-endothelialization, restenosis, and stentthrombosis. JACCCardiovascInterv.2011;4(10):1057-1066. LanskyA, WijnsW, XuB, etal. Targeted therapy with a localised abluminal groove, low-dose sirolimus-eluting, biodegradable polymer coronary stent (TARGET All Comers): a multicentre, open-label, randomised non-inferiority trial. Lancet. 2018;392(10153):1117-1126.

10. Zhu J, Liu H, Cui H, Tang Z, Song C, Zhang R. Safety and efficacy of a novel abluminal groove-filled biodegradable polymer sirolimus-eluting stent. J Mater Sci Mater Med. 2017;28(3):54.

11. Qian J, XuB, Lansky AJ, et al. First report of a novel abluminal groove filled biodegradable polymer rapamycin-eluting stent in de novo coronary artery disease: results of the firstin man FIREHAWK trial. ChinMedJ (Engl). 2012;125(6):970-976.

12. Gao RL, Xu B, Lansky AJ, et al. A randomised comparison of a novel abluminal groove-filled biodegradable polymer sirolimus-eluting stent with a durable polymer everolimus-eluting stent: clinical and angiographic foIlow-up of the TARGET I trial. Eurolntervention. 2013;9(1):75-83.

13. $X u B$, Zhao $Y$, Yang $Y$, et al. Safety and efficacy of a novel abluminal groove-filled biodegradable polymer sirolimus-eluting stent for the treatment of de novo coronarylesions: 12-month results from the TARGETII trial. Chin Med J (Engl). 2014;127(6):1027-1032.

14. Gao Z, Zhang R, Xu B, et al. Safety and efficacy of a novel abluminal groove-filled biodegradable polymer sirolimus-eluting stent for the treatment of de novo coronary lesions: two-year results from a prospective patient-level pooled analysis of TARGET trials. Catheter Cardiovasc Interv. 2015:85:734-743. 
15. Baumbach A, Lansky AJ, Onuma Y, et al. Optical coherence tomography substudy of a prospective multicentre randomised post-market trial to assess the safety and effectiveness of the Firehawk cobalt-chromium coronary stent (rapamycin target-eluting) system for the treatment of atherosclerotic lesions: TARGET All Comers. Eurolntervention. 2018;14(10):1121-1128.

16. Xu B, Zhang YJ, Sun ZW, et al. Comparison of long-term in-stent vascular response between abluminal groove-filled biodegradable polymer sirolimus-eluting stent and durable polymer everolimus-eluting stent: 3-year OCT follow-up from the TARGET I trial. Int I Cardiovasc Imaging. 2015;31(8):1489-1496.

17. Xu B, Saito Y, Baumbach A, et al. 2-Year Clinical Outcomes of an Abluminal Groove-Filled Biodegradable-Polymer Sirolimus-Eluting Stent Compared With a Durable-Polymer Everolimus-Eluting Stent. JACC Cardiovasc Interv. 2019.doi: 10.1016/j.jcin.2019.05.001.
18. Stefanini GG, ByrneRA, Serruys PW, et al. Biodegradable polymer drug-eluting stents reduce the risk of stent thrombosis at 4 years in patients undergoing percutaneous coronary intervention: a pooled analysis of individual patient data from the ISAR-TEST 3, ISAR-TEST 4, and LEADERS randomized trials. Eur Heart J. 2012;33(10):1214-1222.

19. El-Hayek G, Bangalore S, Casso DominguezA, et al. Meta-Analysis of Randomized Clinical Trials Comparing Biodegradable Polymer Drug-Eluting Stent to Second-Generation Durable Polymer Drug-Eluting Stents. JACC Cardiovasc Interv. 2017;10(5):462-473.

20. LiC, Guan C, Zhang R, et al. Safety and efficacy of a novel abluminal groove-filled biodegradable polymer sirolimus-eluting stent for the treatment of de novo coronary lesions: Final five-year results of the patient-level pooled analysis from the TARGET I and TARGET II trials. Catheter CardiovasC Interv. 2019;93:818-824. 